Original Article

\title{
Comparison of the Effects of Exercise Participation on Psychosocial Risk Factors and Cardiovascular Disease in Women
}

\author{
Sun Hur, PhD ${ }^{1)}$, Byung-Jun Cho, $\mathrm{PhD}^{2)^{*}}$, SeOn-Rye Kim, $\mathrm{PhD}^{3)^{*}}$ \\ 1) Division of Sport Science, Kangwon National University, Republic of Korea \\ 2) Department of Emergency Medical Technology, Kangwon National University, Republic of Korea \\ 3) College of Pharmacy, Chungnam National University: 99 Daehakro, Daejeon 305-764, Republic of \\ Korea
}

\begin{abstract}
Purpose] The aim of this study was to research the association of Type D personality with CVD risk factors and psychology through comparison of the association of exercise participation with CVD risk factors and psychological risk factors in women with Type D. [Subjects] This study included 416 middle-aged women. All participants completed the 14-item Type D Scale (DS14) to assess Type D personality. The DS14 consists of two subscales, NA and SI, both of which comprise 7 items. The research subjects were randomly assigned to four groups: Type $\mathrm{D}+$ Exercise $(\mathrm{n}=12)$, Type $\mathrm{D}+$ non-Exercise $(\mathrm{n}=12)$, non-Type $\mathrm{D}+$ Exercise $(\mathrm{n}=12)$, non-Type $\mathrm{D}+$ nonExercise $(\mathrm{n}=10)$. The study consisted of 46 participants. [Methods] An aerobic exercise program and meditation were conducted in parallel for 10 months. Stretching was performed for $10 \mathrm{~min}$ as a warm-up, and then walking and running were performed on a treadmill at the HRmax $60-70 \%$ level for $40 \mathrm{~min}$; this was done three times a week. Blood samples were processed according to standard laboratory procedures. The concentrations of TG and HDL-cholesterol were determined enzymatically on a clinical chemistry analyzer. Blood glucose was measured by the hexokinase method. [Results] Weight, percent fat, social support, and waist circumference showed a significant difference between times in the Exercise groups, and the values were significantly lower than those of the non-Exercise groups. Anxiety and depression showed a significant interaction effect between groups. The average number of CVD risk factors in subjects showed a significant difference between groups. [Conclusion] In conclusion, there were significant differences between groups in terms of CVD risk factors and psychological risk factors in women with Type D personality.

Key words: Psychological, Personality, Exercise
\end{abstract}

(This article was submitted Apr. 3, 2014, and was accepted May 19, 2014)

\section{INTRODUCTION}

Type D personality is characterized by both normal and stable personality traits, negative affectivity (NA, tendency to experience negative emotions), and social inhibition (SI, tendency to inhibit self-expression in social interaction) $)^{1,2)}$. With reference to Type D personality, the health condition of Type D personality people is not six times better than that of non-Type D personality people through the study intended for chronic cardiac disease patients ${ }^{3)}$, through the results of studies intended for heart attack patients, reported that Type D personality was highly related to the onset of cardiovascular disease (CVD) prognosis, death rate and caused a falling-off in quality of life ${ }^{4}$.

Negative emotions are associated with increased pro-

*Corresponding author. Seon-Ryo Kim (E-mail: sjsanj@ hanmail.net)

(C2014 The Society of Physical Therapy Science. Published by IPEC Inc. This is an open-access article distributed under the terms of the Creative Commons Attribution Non-Commercial No Derivatives (by-ncnd) License $<$ http://creativecommons.org/licenses/by-nc-nd/3.0/>. duction of pro-inflammatory cytokines including tumor necrosis factor-alpha (TNF- $\alpha$ ) and interleukin-6 (IL-6) ${ }^{5,6}$. Episodic psychological risk factors such as depression have been associated with poor prognosis in $\mathrm{CVD}^{7,8)}$. Chronic psychological risk factors may also affect clinical manifestations of heart disease ${ }^{9)}$, but individual difference variables like personality traits have received little attention to date in behavioral immunology research ${ }^{10)}$.

Regular aerobic exercise reduces CVD risk factors and levels of oxidative stress and, has a positive influence on lipoprotein metabolism ${ }^{11)}$. Personality type, unlike other psychological factors, is slowly and stably formed from childhood through adulthood and is not easily changed, so psychological factors of Type D personality people are likely formed repeatedly over a comparatively long period of time. They think that it is needed to apply the long-term exercise program over 12 weeks. Also, it was difficult that the results of studies was applied because the main subjects of previous studies was patients with disease. Furthermore, a previous study in patients with disease has investigated the relation between Type D personality and risk factors of CVD, but no previous study has shown Type D personality 
to be associated with increased CVD risk in healthy populations $^{12)}$.

Therefore, the aim of this study was to research the association of Type D personality with CVD risk factors and psychology through comparison of the association of exercise participation with CVD risk factors and psychological risk factors in women with Type D personality.

\section{SUBJECTS AND METHODS}

This study included 416 middle-aged women. All participants completed the 14-item Type D Scale (DS14) to assess Type D personality. The DS14 consists of two subscales, NA and SI, both of which comprise 7 items. A standardized cut-off score $\geq 10$ on both subscales is used to classify Type D personality ${ }^{13)}$. In this study, a Korean version of the DS14 was used ${ }^{13)}$. The Cronbach's $\alpha$ was 0.82 for the NA subscale and 0.80 for the SI subscale. Based on self-reporting, subjects who had gone through menopause, drank alcohol, smoked, or had been performing regular exercise for more than 6 months were excluded from this study. The sample size of this study was estimated prior to data collection by using a power analysis method as previously suggested ${ }^{14)}$. Assuming a medium effect of 0.25 and an alpha level of $0.05, \mathrm{G} *$ Power 3.1 estimated that at least 8 participants were required. All subjects participated voluntarily and gave written informed consent. The 48 participants were classified into one out of four subgroups: Type D+Exercise $(\mathrm{n}=12)$, Type $\mathrm{D}+$ non-Exercise $(\mathrm{n}=12)$, non-Type $\mathrm{D}+$ Exercise $(\mathrm{n}=12)$, non-Type $\mathrm{D}+$ non-Exercise $(\mathrm{n}=10)$. Two subjects refused to participate, and so the final sample consisted of 46 participants. Characteristics of the participants are shown in Table 1.

Social support, anxiety, depression, NA, and SI were chosen as psychosocial risk factors of $\mathrm{CVD}^{15,16)}$. In the Korean version of the social support scale, each item is scored on a 4-point Likert scale ranging from 0 to $3^{17)}$. The Cronbach's alpha of the social support scale was 0.85 . We investigated anxiety using the Korean version of the Spielberger State and Trait Anxiety Inventory (STAI-S). The items of this scale are answered on a 4-point Likert scale from 1 to 4. The Cronbach's $\alpha$ of the STAI-S was 0.83 . The self-rating depression scale ${ }^{12)}$ is a short self-report scale designed to measure depressive symptoms. The questionnaire contains 20 items, and each item is scored on a 4-point scale ranging from 0 to 3. The Cronbach's $\alpha$ of the self-rating depression scale was 0.87 .

SPSS for Windows version 20.0 was used for statistical analysis, and $\mathrm{p}<0.05$ was considered statistically significant. One-way ANOVA was performed for verification of differences between groups with regard to variables measured before the interventions. Two-way repeated ANOVA was performed to examine differences between Type D personality and non-Type D personality after 10 months. In the case of a significant interaction effect between the main effects, the paired t-test was applied between groups by time, and for comparison between groups by time, oneway ANOVA and Duncan's post hoc test were performed.
Table 1. Characteristics of the subjects

\begin{tabular}{lllc}
\hline Variables & Groups & & $\mathrm{M} \pm \mathrm{SD}$ \\
\hline & Type D & Exercise & $47.8 \pm 1.75$ \\
Age & & Non-Exercise & $47.5 \pm 2.50$ \\
(years) & Non-Type D & Exercise & $46.5 \pm 2.43$ \\
& & Non-Exercise & $46.7 \pm 1.90$ \\
& Type D & Exercise & $156.5 \pm 4.93$ \\
Height & & Non-Exercise & $157.1 \pm 4.74$ \\
$(\mathrm{~cm})$ & Non-Type D & Exercise & $157.2 \pm 6.16$ \\
& & Non-Exercise & $157.8 \pm 5.31$ \\
& \multirow{2}{*}{ Type D } & Exercise & $69.2 \pm 9.99$ \\
Weight & & Non-Exercise & $66.8 \pm 8.00$ \\
$(\mathrm{~kg})$ & \multirow{2}{*}{ Non-Type D } & Exercise & $66.4 \pm 4.00$ \\
& & Non-Exercise & $66.8 \pm 3.73$ \\
\hline
\end{tabular}

\section{RESULTS}

The changes in body composition and psychosocial risk factors after exercise for 10 months are shown in Table 2. Weight $(\mathrm{p}=0.026)$ and percent body fat $(\mathrm{p}=0.025)$ showed a significant difference between times, and those of the Exercise groups were significantly lower than those of the non-Exercise groups. Social support showed a significant difference between groups $(\mathrm{p}<0.001)$, and social support in the Type D groups were lower than that in the non-Type D groups; the levels of social support in the Type D+Exercise $(44.42 \pm 8.59$ score) and non-Type D+Exercise (51.50 \pm 8.63 score) groups were significantly increased. Waist circumference $(p<0.001)$ showed a significant difference between groups, and those of the Exercise groups were significantly decreased compared with those of the non-Exercise groups; that of the non-Type D+Exercise group $(87.34 \pm 4.87 \mathrm{~cm})$ was significantly smaller than that of the Type D+Exercise group $(90.94 \pm 5.67 \mathrm{~cm})$.

Anxiety and depression showed a significant interaction effect between groups $(\mathrm{p}<0.001)$ and for group $\times$ time ( $p=0.023, p=0.010$ respectively), and the scores for the Type $\mathrm{D}$ groups were significantly higher than those of the nonType D group in the post-test results; those for the Exercise groups were significantly decreased compared with those of the non-Exercise groups. NA and SI showed a significant difference between groups $(\mathrm{p}<0.001)$ and were significantly decreased in the Type D+Exercise group (11.42 \pm 2.07 and $11.33 \pm 2.35$, respectively). The average number of CVD risk factors in subjects showed a significant difference between groups $(p<0.001)$ and times $(p=0.007)$, and the numbers of CVD risk factors were significantly decreased in the Type $\mathrm{D}+$ Exercise $(1.67 \pm 0.65)$ and non-Type $\mathrm{D}+$ Exercise $(1.08 \pm 0.90)$ groups.

\section{DISCUSSION}

People with a Type D personality have a temperament featuring a lack of positive emotions and so have high selfesteem and high stress responses under certain circumstances ${ }^{18)}$. It is easier for them to feel more depressed than 
Table 2. The changes in body composition and psychosocial risk factors of CVD

\begin{tabular}{|c|c|c|c|c|c|c|}
\hline Variables & Groups & & Before & After & Difference & Duncan \\
\hline \multirow{4}{*}{$\begin{array}{l}\text { Weight } \\
(\mathrm{kg})\end{array}$} & Type D & Exercise & $69.21 \pm 9.99$ & $63.09 \pm 9.62$ & $-6.12 * * *$ & \\
\hline & \multirow{3}{*}{ Non-Type D } & Non-Exercise & $66.81 \pm 8.00$ & $66.69 \pm 8.22$ & -0.12 & \\
\hline & & Exercise & $66.43 \pm 4.00$ & $59.04 \pm 4.59$ & $-7.39 * * *$ & \\
\hline & & Non-Exercise & $66.89 \pm 3.73$ & $67.40 \pm 3.11$ & 0.51 & \\
\hline \multirow{4}{*}{$\begin{array}{l}\text { Percent fat } \\
(\%)\end{array}$} & \multirow[t]{2}{*}{ Type D } & Exercise & $38.02 \pm 5.00$ & $33.41 \pm 5.69$ & $-4.61 * * *$ & \\
\hline & & Non-Exercise & $37.47 \pm 4.31$ & $37.43 \pm 4.21$ & -0.04 & \\
\hline & \multirow[t]{2}{*}{ Non-Type D } & Exercise & $36.68 \pm 3.52$ & $33.34 \pm 3.68$ & $-3.34 * * *$ & \\
\hline & & Non-Exercise & $37.05 \pm 3.03$ & $37.12 \pm 3.25$ & 0.07 & \\
\hline \multirow{5}{*}{$\begin{array}{l}\text { Waist } \\
\text { circumfer- } \\
\text { ence } \\
\text { (cm) }\end{array}$} & \multirow[t]{2}{*}{ Type D } & Exercise & $95.14 \pm 7.07$ & $90.94 \pm 5.67$ & -4.20 & \\
\hline & & Non-Exercise & $96.78 \pm 6.62$ & $97.30 \pm 6.84$ & 0.52 & $\mathrm{c}<\mathrm{a}<\mathrm{d}, \mathrm{b}$ \\
\hline & \multirow[t]{2}{*}{ Non-Type D } & Exercise & $90.43 \pm 6.58$ & $87.34 \pm 4.87$ & -3.09 & \\
\hline & & Non-Exercise & $95.47 \pm 7.74$ & $95.68 \pm 8.03$ & 0.21 & \\
\hline & Type D & Exercise & $1,947.10 \pm 270.32$ & $1,921.38 \pm 251.80$ & -1.32 & \\
\hline \multirow{3}{*}{$\begin{array}{l}\text { Energy } \\
\text { (kcal) }\end{array}$} & \multirow{3}{*}{ Non-Type D } & Non-Exercise & $1,934.54 \pm 266.43$ & $1,926.56 \pm 273.23$ & -0.41 & \\
\hline & & Exercise & $1,927.43 \pm 252.00$ & $1,918.44 \pm 317.12$ & -0.47 & \\
\hline & & Non-Exercise & $1,929.50 \pm 274.00$ & $1,921.81 \pm 306.20$ & -0.40 & \\
\hline \multirow{5}{*}{$\begin{array}{l}\text { Social } \\
\text { support } \\
\text { (score) }\end{array}$} & \multirow[t]{2}{*}{ Type D } & Exercise & $35.58 \pm 9.54$ & $44.42 \pm 8.59$ & 24.85 & \\
\hline & & Non-Exercise & $40.75 \pm 10.00$ & $39.42 \pm 7.83$ & -3.26 & $\mathrm{a}, \mathrm{b}<\mathrm{d}, \mathrm{c}$ \\
\hline & \multirow[t]{2}{*}{ Non-Type D } & Exercise & $47.50 \pm 10.45$ & $51.50 \pm 8.63$ & 8.42 & \\
\hline & & Non-Exercise & $48.60 \pm 8.21$ & $47.70 \pm 7.54$ & -1.85 & \\
\hline & \multirow[t]{2}{*}{ Type D } & Exercise & $56.00 \pm 8.76$ & $47.67 \pm 6.62$ & -14.88 & \\
\hline \multirow{3}{*}{$\begin{array}{l}\text { Anxiety } \\
\text { (score) }\end{array}$} & & Non-Exercise & $56.08 \pm 12.49$ & $61.75 \pm 13.29$ & 10.11 & $\mathrm{c}, \mathrm{d}<\mathrm{a}<\mathrm{b}$ \\
\hline & \multirow[t]{2}{*}{ Non-Type D } & Exercise & $48.25 \pm 6.28$ & $41.08 \pm 3.75$ & -14.86 & \\
\hline & & Non-Exercise & $46.10 \pm 5.53$ & $45.60 \pm 7.29$ & -1.08 & \\
\hline \multirow{4}{*}{$\begin{array}{l}\text { Depression } \\
\text { (score) }\end{array}$} & \multirow[t]{2}{*}{ Type D } & Exercise & $56.25 \pm 8.23$ & $46.17 \pm 7.93$ & -17.92 & \\
\hline & & Non-Exercise & $55.67 \pm 11.80$ & $61.50 \pm 12.80$ & 10.47 & $\mathrm{c}<\mathrm{d}, \mathrm{a}<\mathrm{b}$ \\
\hline & \multirow[t]{2}{*}{ Non-Type D } & Exercise & $46.83 \pm 7.65$ & $39.08 \pm 6.11$ & -16.55 & \\
\hline & & Non-Exercise & $47.10 \pm 5.32$ & $45.60 \pm 5.17$ & -3.18 & \\
\hline \multirow{4}{*}{$\begin{array}{l}\text { Negative } \\
\text { affectivity } \\
\text { (score) }\end{array}$} & \multirow[t]{2}{*}{ Type D } & Exercise & $12.75 \pm 3.17$ & $11.42 \pm 2.07$ & -10.43 & \\
\hline & & Non-Exercise & $16.33 \pm 4.48$ & $16.42 \pm 4.25$ & 0.55 & $\mathrm{c}, \mathrm{d}<\mathrm{a}<\mathrm{b}$ \\
\hline & \multirow[t]{2}{*}{ Non-Type D } & Exercise & $4.92 \pm 3.65$ & $4.75 \pm 3.52$ & -3.46 & \\
\hline & & Non-Exercise & $5.40 \pm 3.27$ & $5.60 \pm 3.53$ & 3.70 & \\
\hline \multirow{4}{*}{$\begin{array}{l}\text { Social } \\
\text { inhibition } \\
\text { (score) }\end{array}$} & \multirow[t]{2}{*}{ Type D } & Exercise & $12.75 \pm 3.11$ & $11.33 \pm 2.35$ & -11.14 & \\
\hline & & Non-Exercise & $15.75 \pm 4.59$ & $16.17 \pm 4.47$ & 2.67 & $\mathrm{c}, \mathrm{d}<\mathrm{a}<\mathrm{b}$ \\
\hline & \multirow[t]{2}{*}{ Non-Type D } & Exercise & $4.50 \pm 3.45$ & $4.33 \pm 3.26$ & -3.78 & \\
\hline & & Non-Exercise & $4.40 \pm 2.55$ & $4.60 \pm 2.88$ & 4.55 & \\
\hline & Type D & Exercise & $2.67 \pm 0.98$ & $1.67 \pm 0.65$ & $-37.45^{*}$ & \\
\hline $\begin{array}{l}\text { CVD } \\
\text { risk }\end{array}$ & & Non-Exercise & $2.75 \pm 1.06$ & $2.75 \pm 0.97$ & 0.00 & $\mathrm{c}<\mathrm{a}<\mathrm{d}, \mathrm{b}$ \\
\hline $\begin{array}{l}\text { risk } \\
\text { (n) }\end{array}$ & Non-Type D & Exercise & $1.92 \pm 0.51$ & $1.08 \pm 0.90$ & $-43.75^{* *}$ & \\
\hline & & Non-Exercise & $2.45 \pm 0.69$ & $2.36 \pm 0.81$ & -3.67 & \\
\hline
\end{tabular}

Mean \pm SD. ${ }^{* * *} \mathrm{p}<0.001 ;{ }^{* *} \mathrm{p}<0.01 ;{ }^{*} \mathrm{p}<0.05$ (paired t-test). a, Type D+Exercise $(\mathrm{n}=12) ; \mathrm{b}$, Type $\mathrm{D}+$ Non-Exercise $(\mathrm{n}=12)$ c, Non-Type D+Exercise $(n=12)$; , Non-Type $D+$ Non-Exercise $(n=10)$

people with non-Type D personality, and they tend to have a very low life satisfaction ${ }^{4}$. Apart from negative emotions, social inhibition may also impact the immune system ${ }^{19)}$. In relation to health problems, Type D personality is a factor causing occurrence of CVD and poor prognosis ${ }^{4,19)}$.

In a previous study, the heart rates of the heart rate recovery at one minute of rest (HRR-1) $\leq 18 \mathrm{bpm}$ group was significantly lower than that of the HRR-1>18 bpm group during exercise, and most of the subjects had a Type D per- sonality; it was also particularly confirmed that they had high SI tendencies ${ }^{20)}$. But after a cardiac rehabilitation program for 12 weeks, maximum aerobic exercise capacity, left ventricular ejection fraction, exhaustion time, and Type D character variables did not show significant differences between groups ${ }^{2)}$. Milani and Lavie reported that as CVD patients can have low cardiorespiratory function, the effect of exercise training for three months is insufficient ${ }^{21}$. CVD patients have various CVD risk factors, and they need more 
long-term exercise training rather than a higher exercise intensity in order to reduce the CVD risk factors. Therefore, application of the long-term exercise program conducted in this study is effective in improving CVD risk factors ${ }^{22)}$.

Through studies on Type D personality and the effects of exercise programs, the Type D personality score was found to decrease and quality of life was found to increase after a cardiac rehabilitation program ${ }^{23}$. Anxiety and depression scores in people with Type D personality decreased after a three-month cardiac rehabilitation program ${ }^{3}$.

After long-term exercise training in this study, the Exercise groups showed decreased degrees of anxiety and depression, while the non-Exercise groups showed significant increases. Therefore, we found that aerobic exercise and meditation were effective for decreasing anxiety and depression. Depression and anxiety appear to be higher in individuals with CVD than on those that are healthy, but it is ambiguous whether this is the result of illness or the result of original personality traits. However, as in the present study, depression and anxiety in the general population can be interpreted as the results of personality maladjustment unrelated to disease.

Psychological factors may also promote immune dysregulation. It has been suggested that a dysregulated cytokine network is implicated in the pathophysiology of emotional distress in coronary artery disease ${ }^{24,25)}$. Programs need to be developed that can raise the awareness associated with dietary habits, care for health control behaviors, health-related behaviors, the effort for health in diet, etc., and to manage stress, motivators and opportunities should be diversified that can strongly take advantage of sound programs such as those incorporating various movements in daily life, singing classes, yoga, meditation, etc., which have already been developed and are widely available. The muscle output during simultaneous contraction was larger than that of each individual muscle, suggesting that it is easier to contract the LA when the TA is contracted from the atandpoint of the kinetic chain ${ }^{26)}$.

The limitations of the present study include its relatively small sample size. In addition, the findings from the study results were somewhat limited by the small sample sizes for the groups. However, the present study has extended the existing research on Type D personality in several respects, including intervention and social support.

\section{REFERENCES}

1) Denollet J: DS14: standard assessment of negative affectivity, social inhibition, and Type D personality. Psychosom Med, 2005, 67: 89-97. [Medline] [CrossRef]

2) Denollet J, Schiffer AA, Spek V: A general propensity to psychologica distress affects cardiovascular outcomes: evidence from research on the type D (distressed) personality profile. Circ Cardiovasc Qual Outcomes, 2010, 3: 546-557. [Medline] [CrossRef]

3) Pelle AJ, Schiffer AA, Smith OR, et al.: Inadequate consultation behavior modulates the relationship between type D personality and impaired health status in chronic heart failure. Int J Cardiol, 2010, 142: 65-71. [Medline] [CrossRef]

4) Pedersen SS, Denollet J: Validity of the Type D personality construct in Danish post-MI patients and healthy controls. J Psychosom Res, 2004, 57
265-272. [Medline] [CrossRef]

5) Kiecolt-Glaser JK, McGuire L, Robles TF, et al.: Emotions, morbidity, and mortality: new perspectives from psychoneuroimmunology. Annu Rev Psychol, 2002, 53: 83-107. [Medline] [CrossRef]

6) Torre-Amione G: Immune activation in chronic heart failure. Am J Cardiol, 2005, 95: 3C-8C, discussion 38C-40C. [Medline] [CrossRef]

7) Faris R, Purcell H, Henein MY, et al.: Clinical depression is common and significantly associated with reduced survival in patients with non-ischaemic heart failure. Eur J Heart Fail, 2002, 4: 541-551. [Medline] [CrossRef]

8) Vaccarino V, Kasl SV, Abramson J, et al.: Depressive symptoms and risk of functional decline and death in patients with heart failure. J Am Coll Cardiol, 2001, 38: 199-205. [Medline] [CrossRef]

9) Conraads VM, Jorens PG, De Clerck LS, et al: Selective intestinal decontamination in advanced chronic heart failure: a pilot trial. Eur J Heart Fail, 2004, 6: 483-491. [Medline] [CrossRef]

10) Hansson GK: Inflammation, atherosclerosis, and coronary artery disease. N Engl J Med, 2005, 352: 1685-1695. [Medline] [CrossRef]

11) So WY, Choi DH: Effects of walking and resistance training on the body composition, cardiorespiratory function, physical fitness and blood profiles of middle-aged obese women. Exe Sci, 2007, 16: 85-94.

12) Nam CW: Association between type $D$ personality and risk factors for cardiovascular disease in healthy adults. Master's degree paper. Department of Medicine, Graduate School Pusan National University, 2011.

13) Lim HE, Lee MS, Ko YH, et al.: Assessment of the type D personality construct in the Korean population: a validation study of the Korean DS14. J Korean Med Sci, 2011, 26: 116-123. [Medline] [CrossRef]

14) Faul F, Erdfelder E, Buchner A, et al.: Statistical power analyses using G*Power 3.1: tests for correlation and regression analyses. Behav Res Methods, 2009, 41: 1149-1160. [Medline] [CrossRef]

15) Mommersteeg PM, Kupper N, Denollet J: Type D personality is associated with increased metabolic syndrome prevalence and an unhealthy lifestyle in a cross-sectional Dutch community sample. BMC Public Health, 2010, 10: 714-720. [Medline] [CrossRef]

16) Volz A, Schmid JP, Zwahlen M, et al.: Predictors of readmission and health related quality of life in patients with chronic heart failure: a comparison of different psychosocial aspects. J Behav Med, 2011, 34: 13-22. [Medline] [CrossRef]

17) Song MR, Kim EK, Yu SJ: A study of ADL, social support, self-efficacy between the aged groups with and without depression. Kor J Soci Welf Res, 2010, 24: 61-80.

18) Habra ME, Linden W, Anderson JC, et al.: Type D personality is related to cardiovascular and neuroendocrine reactivity to acute stress. J Psychosom Res, 2003, 55: 235-245. [Medline] [CrossRef]

19) Denollet J, Conraads VM, Brutsaert DL, et al.: Cytokines and immune activation in systolic heart failure: the role of Type D personality. Brain Behav Immun, 2003, 17: 304-309. [Medline] [CrossRef]

20) von Känel R, Barth J, Kohls S, et al.: Heart rate recovery after exercise in chronic heart failure: role of vital exhaustion and type D personality. J Cardiol, 2009, 53: 248-256. [Medline] [CrossRef]

21) Milani RV, Lavie CJ: Prevalence and profile of metabolic syndrome in patients following acute coronary events and effects of therapeutic lifestyle change with cardiac rehabilitation. Am J Cardiol, 2003, 92: 50-54. [Medline] [CrossRef]

22) Gayda M, Brun C, Juneau M, et al.: Long-term cardiac rehabilitation and exercise training programs improve metabolic parameters in metabolic syndrome patients with and without coronary heart disease. Nutr Metab Cardiovasc Dis, 2008, 18: 142-151. [Medline] [CrossRef]

23) Karlsson MR, Edström-Plüss C, Held C, et al.: Effects of expanded cardiac rehabilitation on psychosocial status in coronary artery disease with focus on type D characteristics. J Behav Med, 2007, 30: 253-261. [Medline] [CrossRef]

24) Gidron Y, Gilutz H, Berger R, et al.: Molecular and cellular interface between behavior and acute coronary syndromes. Cardiovasc Res, 2002, 56: 15-21. [Medline] [CrossRef]

25) Kop WJ: The integration of cardiovascular behavioral medicine and psychoneuroimmunology: new developments based on converging research fields. Brain Behav Immun, 2003, 17: 233-237. [Medline] [CrossRef]

26) Tajiri K, Huo M, Akiyama $S$, et al.: Measurement reliability and kinetic chain of the thickness of the transverse abdominal muscle and action potential of the levator ani muscle. J Phys Ther Sci, 2010, 22: 451-454. [CrossRef] 